\title{
Rethinking interaction in social distancing times: implications for business-to-business companies
}

\author{
Andrea Runfola \\ Department of Economics, University of Perugia, Perugia, Italy, and \\ Matilde Milanesi and Simone Guercini \\ Department of Economics and Management, University of Florence, Florence, Italy
}

\begin{abstract}
Purpose - This paper aims to investigate how the COVID-19 pandemic has affected the interaction in a business-to-business (BtoB) setting and the emerging relational dynamics. The COVID-19 pandemic is having a strong impact on BtoB markets in terms of the stop of production, the difficulty of coping with payments, restrictions on the flows of people and goods within national and international markets. The paper discusses that the effects of worldwide lockdowns, social distancing and other related restrictions undermine one of the salient features of business relationships, namely interaction.

Design/methodology/approach - The paper relies on a qualitative interpretivist approach based on the data collected from in-depth interviews with key informants and secondary sources. The fashion industry is taken as an emblematic case, given the relevance of BtoB relationships, especially those between global fashion brands and their suppliers, and the dramatic impact of the pandemic.

Findings - The paper shows four effects in terms of relational dynamics. The freezing effect is the maintaining of interaction at minimum operating levels capable of ensuring survival for both interacting actors. The ripple effect can be conceived as a negative effect of the pandemic related to the weakening of the freezing effects in interactions along the supply chain. The rebound effect is a sudden increase in interactive processes among existing relationships. The vicious effect is a negative effect of the pandemic on the interaction that refers to the decay of existing interaction and their ending.

Originality/value - This study fits into the current period of the COVID-19 pandemic to stress the role of interaction involving people and businesses as a key to restart. The paper suggests managerial implications to respond to the pandemic in the short term and to set the basis for future opportunities.
\end{abstract}

Keywords Interaction, Supply chain, Fashion industry, Relational dynamics, COVID-19

Paper type Research paper

\section{Introduction}

This paper investigates how the COVID-19 pandemic has affected interaction in a business-to-business (BtoB) setting and the emerging relational dynamics. The paper draws on the interaction theory from the industrial marketing literature and links it to the main consequences of the COVID-19 pandemic, to bring out some theoretical implications as well as guidelines for practitioners, managers and entrepreneurs.

The COVID-19 phenomenon can be compared with categories already formulated in the extant literature, such as the "black swan" (Taleb, 2007) or the "outlier" (Crawford et al., 2017), which discuss how it is possible to be prepared for unpredictable events and partially overcome the vulnerability of people, society and economic systems. The pandemic is rapidly involving industrial markets, both directly, due to the need to

The current issue and full text archive of this journal is available on Emerald Insight at: https://www.emerald.com/insight/0885-8624.htm

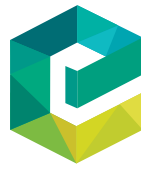

Journal of Business \& Industrial Marketing 36/13 (2021) 105-115

Emerald Publishing Limited [ISSN 0885-8624] [DOI 10.1108/JBIM-05-2020-0242] stop production during lockdown periods, and indirectly, especially for suppliers of companies offering consumer goods (Rapaccini et al., 2020). We are all experiencing a phenomenon that is involving a huge number of countries and people, characterized by the rapidity of change of the health situation, the socio-economic and organizational one. From a recent McKinsey[1] survey, the impact of such changes on companies is severe, and a large part of companies is adopting new practices, with particular importance assigned to digitalmediated interaction. Digitalization has already been recognized as a key trend in sales activity (Khusainova et al.,

\footnotetext{
(C) Andrea Runfola, Matilde Milanesi and Simone Guercini. Published by Emerald Publishing Limited. This article is published under the Creative Commons Attribution (CC BY 4.0) licence. Anyone may reproduce, distribute, translate and create derivative works of this article (for both commercial and non-commercial purposes), subject to full attribution to the original publication and authors. The full terms of this licence may be seen at http://creativecommons.org/licences/by/4.0/legalcode
}

Received 16 May 2020

Revised 9 November 2020

23 January 2021

12 March 2021

Accepted 5 April 2021 
2018) and in research on selling (McGowan, 2020a), but the dynamics of that trend have seen a leap with the pandemic diffusion. The McKinsey survey states that BtoB companies have transferred a significant part of their sales to remote sales models, and about $80 \%$ of European BtoB companies have moved at least a part of their sales via videoconference or telephone. The impact of the pandemic on BtoB companies is confirmed by a recent contribution by Cortez and Johnston (2020) that discusses the disastrous effects of the COVID-19 virus in terms of intra- and inter-organizational tension, demanding new approaches for managing business operations.

In BtoB settings, the COVID-19 pandemic is affecting supply chains, especially relationships with suppliers in those countries in which the virus started first, such as China; demand, for the sharp drop in orders from business-toconsumer (BtoC) companies; production, for the partial or total closure of production facilities; social relationships and face-to-face communication (Kumar et al., 2020; Ivanov and Dolgui, 2020). Thus, while in the medium/long term, different scenarios may occur, in the short term, there is a fast-evolving scenario that requires companies to operate in conditions of greater uncertainty. Hence, the interaction in this context relates to uncertainty, at the same time offering points of reference but also propagating the effects of the crisis through interdependence in the business network. The interaction is, therefore, at the same time a factor that can produce uncertainty and the context in which it can be faced during the pandemic.

In this scenario, scholars have stressed the importance of the ability to make inter-organizational teams functioning effectively (Sluss and Poweley, 2020), as well as communication skills with the customer (Argenti, 2020). The COVID-19 virus keeps people distant and hinders social relationships, as an effect of social distancing, but it also puts under pressure the relationships between companies, also due to the re-emergence of international tensions that hinder the functioning of the global value chains (Gereffi, 2020). The use of digital tools may be enhanced in COVID-19 times, as it offers solutions for interacting. At the same time, it may hinder some fundamental features of interaction in BtoB settings, because interaction has always been related to face-to-face personal contacts.

Starting from this background, the paper relies on the interaction theory developed within the industrial marketing studies (Håkansson and Östberg, 1975; Håkansson, 1982; Håkansson et al., 2009) to investigate how the COVID-19 pandemic has affected interaction in a BtoB setting and the emerging relational dynamics. As this period of change requires managing uncertainty, interacting is a way to deal with interdependence, even more under conditions of uncertainty (Walsh, 2020). Relational dynamics may derive from relationship stress (Holmlund-Rytkönen and Strandvik, 2005), which can be considered as critical events that generate tension and stress among actors over time, and that may imply different consequences for interaction, from strengthening to the end (Tahtinen and Halinen, 2002). The COVID-19 pandemic can surely be considered as an unheard-of event, a "critical time" (Edvardsson and Strandvik, 2009) for the management of business relationships (Cortez and Johnston, 2020; Crick and Crick, 2020). However, the interplay between interaction and high-impact events (crisis) is an under-investigated topic in
BtoB marketing. Recent literature stresses the relevance of depicting how relationships and interaction evolve during the pandemic and the relevance of understanding new responses in BtoB markets (Kang et al., 2020). Moreover, even policymakers and institutions at different levels underlined how this issue is now more than ever important because of the need to find new answers for what has been identified as the new phase that implies the transition to new normality (UNCTAD, 2020 , p. 1) in which relationships in production networks should be the subject of a profound reconsideration after the pandemic. Thus, this paper aims at contributing to this issue by answering the following research questions:

RQ1. How does the COVID-19 pandemic shape the interaction in BtoB settings?

RQ2. What types of relational dynamics stem from a pandemic crisis?

The paper takes the fashion industry as an emblematic case. The fashion industry is characterized by high levels of interaction between BtoB actors (especially global fashion brands and their suppliers) and globalization and has experienced, more than other industries, the abrupt change due to the pandemic (Brydges et al., 2020). Additionally, the fashion industry has also been the authors' field of study for the past 20 years and, therefore, the experience gained in the field allows the authors to provide a more complete and in-depth view of the subject under investigation. Methodologically, the paper adopts a qualitative interpretivist approach based on oneto-one interviews with key informants from the fashion industry, supplemented with secondary data. The paper is structured as follows: the next section outlines the theoretical background, while in Section 3, the methodology is presented. Sections 4 and 5 focus on the fashion industry, the impact of the COVID-19 pandemic on the industry as a whole and the interaction between actors, especially buyers and suppliers. The paper ends with a discussion of findings and provides managerial implications.

\section{Interaction and uncertainty in business-to- business research}

With the emergence of the interaction theory during the 1970s and 1989s (Håkansson and Östberg, 1975; Håkansson,1982), the idea that interaction between significant actors is a primary characteristic of the business landscape becomes a central construct in the research carried out by the Industrial Marketing and Purchasing (IMP) group. The attention shifts from what is going on within a company to what happens between companies (Ford et al., 2008), which constitutes the doing of business. Håkansson et al. (2009, p.33) conceptualize interaction as "an important economic process through which all of the aspects of business, including physical, financial and human resources, take their form, are changed and are transformed."

Moreover, the network metaphor depicts the shape of the business landscape characterized by connections between interactions (Håkansson et al., 2009). Thus, the interaction may involve actors in long-term relationships characterized by continuity over time (Håkansson and Snehota, 1995). 
Interaction leads to mutual adaptation of counterparts' activities and resources, in a dynamic process, "driven by previous interactions and which drives those which may follow from it" (Håkansson and Ford, 2016, p.155). Such interactions aim to bring together the skills and capabilities of the counterparts, and so an interaction process is likely to activate different combinations of teaching and learning expressed through continuing proposals and responses (Guercini and Runfola, 2015).

It has been argued that "on one hand, relationships are built to decrease uncertainty and increase stability. On the other hand, relationships are the source of change" (Freytag and Ritter, 2005, p. 646). Accordingly, researchers have directed their attention to analyzing change dynamics in business networks. Changes concern relational dynamics that do not alter the network structure, or relational dynamics that change the structure of the network, when relationships are established or ended (Guercini and Milanesi, 2019). In other words, relational dynamics include all the changes that originate on a relationship level between the counterparts of interaction, which in turn can influence the larger business network in which at least one counterpart is embedded (Tunisini and Bocconcelli, 2009).

In this stream of research, it has been discussed that there could be a discontinuity in the interaction, which means a nonlinearity of interactive processes related to the more general concepts of stability and change in business networks (Runfola et al., 2013). Critical incidents may intervene and have severe consequences for interaction (Halinen and Törnroos, 1998). Different relational paths, such as the creation of new business relationships (activation) or the ending of existing relationships (substitution), may emerge (Guercini and Runfola, 2012; Guercini and Milanesi, 2019). Within the industrial marketing literature, previous contributions have considered different constructs to identify the paths that may intervene. It has been considered the consequences of interaction dynamics in terms of relationships strengthening (Holmlund-Rytkönen and Strandvik, 2005) or thickening (Håkansson, 2006), when the interaction becomes more direct and intense, versus relationships weakening (Holmlund-Rytkönen and Strandvik, 2005), or a progressive reduction of interaction that leads to relationships fading (Gronhaug et al., 1999; Olkkonen and Tuominen, 2008), as well as a relationship ending with the closure of the relationships (Havila and Medlin, 2012).

Moreover, it has been pointed out how these dynamics may be intentionally derived from actors' behaviors or be forced by exogenous events (Ping and Dwyer, 1992). The COVID-19 pandemic represents an unprecedented event in this sense, which generates a high degree of uncertainty and tension in the interaction among actors. As is known, uncertainty is very difficult to measure, varies based on its sources and how it is experienced and includes different dimensions and levels, such as environmental, industry and firm uncertainty (Sharma et al., 2020). A relevant type is relational uncertainty, defined as the "inability to predict and explain the actions of a partnering organisation due to a lack of knowledge about their abilities and intentions" (Kreye, 2018, p. 91). The COVID-19 pandemic generates an environmental uncertainty, namely, an unpredictability of the external environment (Milliken, 1987), which negatively influences the relational uncertainty.
Additionally, interaction is also put under pressure by the social distancing made necessary by the pandemic. The relationship between uncertainty and interaction has been studied concerning the effectuation logic adopted by entrepreneurial actors (McGowan, 2020b). The effectuation process was developed by Sarasvathy (2009) starting from the comparison with the causation process (Sarasvathy, 2001).

The two processes, causation and effectuation, concern how the actors face problems to give them a solution. In the case of causation, the actor starts from the desired effects and, consequently, chooses among the possible means to achieve them. It follows that the logic of causation is predictive, as it is based on the possibility of predicting the effects of using the available means. Instead, in the case of effectuation, the actor focuses on the available means and, consequently, selects among the possible effects that can be achieved starting from that set of means. Effectuation is, therefore, adaptive. The example of the chef who has to prepare dinner is particularly effective: under a causation logic, he/she starts from the menu to be created to define the ingredients needed; under an effectuation logic, he/she starts from the available ingredients to select the possible menus that can be prepared (Sarasvathy, 2001, p. 245). Interaction generates resources that can represent the starting point of effectuation and, in general, have interdependencies that hinder a predictive logic, if played by a single actor. Effectuation is seen as a way to deal with uncertainty, especially on the part of entrepreneurial actors who do not have substantial resources (Read et al., 2009). Research shows that over time, the use of the logic of execution by the actors in the interaction does not favor the reduction of uncertainty (McGowan, 2020b). The interdependence that characterizes relationships with other actors means loss of control on the part of the individual actor while also indicating a way to address problems, through adaptation and innovation.

Therefore, what happens to interaction in social distancing times? If interaction includes physical, financial and human resources that are changed and transformed, the global lockdown due to the pandemic significantly limits, and slows down, the exchange of resources and the performance of activities that are the basis of the interaction. The human and physical form of interaction, through interpersonal communication or delivering of physical products and services, is inhibited by social distancing and by the impossibility of moving locally and globally. The transformation takes the forms of the use of digital devices, already tested and growing before the need for distancing (Khusainova et al., 2018) but which become an essential, although not unique channel. Recent academic debate wonders how digital tools may be integrated with non-digital forms of communication (such as face to face) in BtoB interactions (Krings et al., 2021). The COVID-19 represents in this sense a challenge, where digital tools have been considered to play a supporting role in contributing to the survival of BtoB companies during the outbreak, enhancing some activities in buyer-seller interactions (Cortez and Johnston, 2020). Moreover, it has been noted how the implementation of digital tools is still in infancy and evolution within the digital transformation issue of BtoB companies (Wengler et al., 2021).

A further aspect concerns the loss of the possibility of forecasts due to the growing uncertainty, which makes the 
forecasts previously made with the use of sophisticated data and calculation tools completely unreliable, and pushes toward the use of less analytical forms of judgment that can, however, be found a field of application in interaction (Guercini, 2019). The adoption of these methods of forming judgments and, therefore, of the evolution of behavior, assumes characteristics that are affected by the need for adaptation to a changed context, which remains, however, characterized by interdependence between the actors (Johanson and Mattsson, 1987; Baptista, 2013). According to Möller and Wilson (1995), exchange processes can be divided into resource exchange (e.g. product, service, technology, information, financial resources) and social exchange (e.g. beliefs, attitudes, values, norms, goals). Barriers to movements and socialization make it hard to activate exchange processes and bring together the skills and capabilities of the counterparts. Lastly, many companies are expected to experience major crises, or bankruptcies, with obvious consequences on their counterparts: discontinuity and critical incidents may become constant in the interactive processes.

\section{Methodology}

This study draws on the past decades of research carried out by the authors on the fashion industry, enriched with 15 in-depth interviews with key informants, supplemented with secondary data. The fashion industry is taken as an emblematic case which could allow setting guidelines also in other BtoB areas characterized by high levels of interaction between BtoB actors. Currently, the industry is strongly affected by the COVID-19 pandemic. As the pandemic is a fast-evolving phenomenon, an explorative approach (Eisenhardt and Graebner, 2007) was preferred. More specifically, the authors opted for a qualitative interpretivist approach based on one-to-one interviews. Such an approach lies in the qualitative research domain and was selected for its emphasis on contextual conditions in which events take place. Additionally, the qualitative interpretivist approach focuses on actors, what they think, feel, their experience and perceptions of the subject under investigation (Denzin and Lincoln, 2008). A quantitative approach was avoided because authors believe it would have limited the understanding of complex, pervasive, current and rapidly changing phenomena such as the COVID-19 pandemic, which can hardly be limited to variables and attributes.

The research was carried out in several steps. First, preliminary observations were included as part of the research design aimed at increasing the validity of the study. Preliminary observation also allowed, creating trust among the participants and find "gatekeepers" to have access to respondents and establish relationships so that respondents feel comfortable giving information (Creswell and Miller, 2000). The preliminary observation started in February 2020, when the COVID-19 virus first appeared in China and consisted of the participation of members of the research team in events and thematic workshops (in-person and online) organized by groups and associations in the fashion industry. The preliminary observation resulted in social activities that favored the interaction with entrepreneurs and managers in a less formal way that helped build a communication channel and foster the researcher-manager interface (Guercini, 2004). The most relevant conversations and speeches were recorded as field notes. The preliminary observation allowed a better understanding of the pandemic and its impact on the fashion industry and provided a basis for developing the next steps of the research. It was also functional to the identification of some potential key informants and the validation of a set of selection criteria, which were defined as the following:

- lasting experience (at least five years) in the fashion industry to ensure a longitudinal perspective on the industry and its present evolution;

- top positions in such companies; and

- entrepreneurs and managers belonging to companies operating at different levels of the fashion pipeline (global fashion brands, first- and second-tier suppliers) to ensure an interactive perspective.

Based on these criteria, eight key informants were selected. The availability of key informants was fundamental to the selection process, due to the sensitivity of the topic under investigation and the agitated period, of great difficulty and uncertainty for companies.

The second step of the research included data collection through one-to-one in-depth interviews with key informants. Fifteen semi-structured interviews were conducted with the selected informants, whose roles and other information about their companies are summarized in Table 1. Respondents' membership to different fashion companies guaranteed multiple perspectives on the impact of the COVID-19 pandemic on BtoB interactions, allowed an interactive perspective and limited self-reported biases that may compromise the reliability of the research. The interview guideline included four sections as follows: respondents' profile and brief company profile, the impact of the pandemic on the fashion industry and their company, the impact of the pandemic on BtoB relationships, relevant BtoB relationships heavily impacted by the pandemic and reactions. Interviews were conducted via Skype and GMeet from mid-2020, just after the end of the first lockdown in Italy. All the respondents (and companies) are Italian, but their companies have a global or at least international, profile as fashion companies or suppliers of global fashion companies. The interviews were conducted in Italian and then translated into English. Each interview lasted between 45 and $120 \mathrm{~min}$, recorded and transcribed.

Interviews were supplemented with secondary data collected from February to October 2020 from multiple sources: reports on the fashion industry published by large consulting companies (e.g. McKinsey, PWC, Bain \& Company), articles published in specialized fashion press (e.g. Pambianco Magazine, Fashion Magazine, Business of Fashion, Vogue Business), articles published on generalist press, videointerviews to entrepreneurs and managers published on YouTube and other social media.

Concerning data analysis, interview transcripts were fully read by each member of the research team to provide subjective interpretation and systematization in recurrent categories. After that, during a meeting that involved all members of the research group, the subjective interpretations were compared, discussed and challenged, to verify that the interpretations respected the actual words of the interviewees, without distortion. This 
Table 1 Key informants and interviews

\begin{tabular}{|c|c|c|}
\hline Respondents' & Position & $\begin{array}{c}\text { No. of } \\
\text { interviews }\end{array}$ \\
\hline R1 & $\begin{array}{l}\text { Chief commercial officer in a global } \\
\text { luxury fashion company }\end{array}$ & 2 \\
\hline $\mathrm{R} 2$ & $\begin{array}{l}\text { Marketing manager in a company that } \\
\text { works as supplier (accessories) in the } \\
\text { fashion industry }\end{array}$ & 2 \\
\hline R3 & $\begin{array}{l}\text { Entrepreneur in a company that works } \\
\text { as supplier (metal accessories) in the } \\
\text { fashion industry }\end{array}$ & 2 \\
\hline R4 & $\begin{array}{l}\text { Entrepreneur in an international luxury } \\
\text { fashion company }\end{array}$ & 3 \\
\hline R5 & $\begin{array}{l}\text { Consultant (design and production) in } \\
\text { the fashion industry }\end{array}$ & 1 \\
\hline R6 & $\begin{array}{l}\text { Entrepreneur in a company that } \\
\text { produces luxury leather bags and works } \\
\text { also as supplier in the fashion industry - } \\
\text { vice president of a national association } \\
\text { of leather manufacturers }\end{array}$ & 3 \\
\hline R7 & $\begin{array}{l}\text { Consultant (marketing) in the fashion } \\
\text { industry }\end{array}$ & 1 \\
\hline R8 & $\begin{array}{l}\text { Supply chain manager of a global luxury } \\
\text { fashion company }\end{array}$ & 1 \\
\hline
\end{tabular}

interpretative attempt resulted in the creation of categories (recurring topics) based on the content of interviews, and the related quotes were extracted. The results are presented in Section 5. The same procedure was followed for the secondary data that was fully read and systematized by each author, and then confronted and discussed. The past research experiences of the authors in the fashion industry have been valued in enriching the secondary data. This interpretative effort resulted in the understanding of the impact of the COVID-19 pandemic on the fashion industry, described in the following section.

\section{The pandemic and the fashion industry: what is happening?}

The reasons that see the fashion industry in the eye of the storm are manifold. First, the forced closure of stores all over the world and the stop to international tourism that contributes to shopping in airports and large cities. Then, the impossibility of presenting the collections at fashion shows. Milan Fashion Week ended behind closed doors and, in part, in streaming. Subsequent events, between Paris and Dubai, have also been postponed to a later date. The main sector trade fairs have also been postponed, as are the men's collections, which will be presented at fashion shows together with the women's ones. In light of these ongoing dynamics, Vogue Business[2] estimates an overall loss of turnover of US $\$ 40 \mathrm{bn}$ in 2020. Pambianco[3] shows not only a collapse in sales but also a collapse in the stock exchange. In Europe, the 27 main fashion brands that at the end of the year 2019 capitalized a total of $€ 719 \mathrm{bn}$, lost $37.09 \%$ of their value, equal to $€ 195 \mathrm{bn}$, between February 21 and April 3. The industry itself understands the need to rethink and reconvert. "Slowing down and realigning" are the keywords of a letter-manifesto by Giorgio Armani sent to WWD (Women's
Wear Daily) magazine, which calls for a rethinking of the business models that put people and authenticity at the center. This reflection is extended to the BtoB markets and the supply chains, put under great pressure by the pandemic and the consequent lockdown. Great difficulties are being experienced by companies operating at various levels of the fashion supply chain (yarns, fabrics, garment making, to name a few): blocking of supplies, significant reductions in turnover, shortage of cash, risk of unfair competition, problems in managing relationships with the main customers, such as the major fashion and luxury brands. For these reasons, the fashion industry appears as an emblematic case to explain the relational dynamics in social distancing times.

\section{Interactive processes in the fashion industry}

Fashion is a remarkable example of a globalized sector, with production alternatives on an international scale, a multiplicity of actors involved in the supply chains, frequent changes in consumption and a frenetic pace of product innovation. The COVID-19 pandemic acts in this context on several key sector activities, all characterized by frequent interactions between the players in the BtoB markets. Interaction strongly characterizes the key processes of the fashion system, affecting the effectiveness of the activities related to the design of the new collections, the supply/manufacturing decisions and the relationships between many actors, including global companies with leading fashion brands, local manufacturers and subsuppliers. The creation of new collections in the fashion industry represents a pivotal moment in which interaction comes into play between business actors:

As first-tier suppliers, we have close relationships with global fashion brands
for the design of new collections. There is the need to "touch" the product
(for example, the semi-finished product). That's why the designers of global
fashion brands came very often to visit the suppliers to touch the semi-
finished products, check the samples, and define together many
characteristics of the new collection. Remote management of these
processes is hard, but, as a company, we are implementing digital
technologies and frequent virtual meetings are helpful (R3). The design of the collections represents a crucial moment in the life of fashion companies, for which interactive processes require travels, meetings, company visits and social moments that are essential to understand the potential of a new collection, contributing to determine its creative dimension.

There are business relationships, but there are also social relationships, which can hardly be replicated remotely or on digital media. These are then two sides of the same coin for an effective fashion design process (R7).

Similarly, the production dimension is subject to profound stress from the new scenarios proposed by the pandemic. Over the decades, the fashion industry has been affected by the process of globalization of supply and manufacturing processes, with frequent offshoring and outsourcing processes. Interactive processes have, therefore, found their context at the international level, with global companies engaged in the attempt to reconcile strategic alternatives of local and global sourcing/manufacturing, mostly solved through different mixes based on service contents offered by suppliers as well as aspects related to costs. The process of decentralization of production at the international level concerns the need to rethink the management model of supply/production processes on a global scale, with the rise of new phenomena such as reshoring or back 
sourcing that place the attention to proximity, closer interactions with local suppliers and a local production logic. When it comes to Italy, a characteristic of the fashion industry is the co-presence within the same territory (industrial districts) of both big brands acting as leading global players and smalland medium-sized local companies, working as first-, secondand third-tier suppliers, characterized by a highly crafted vocation and know-how. Local companies in the leather industry aim to be strategic partners of lead global companies, through maintaining tacit knowledge and know-how, enriched with production capabilities and new skills:

Local producers are essential for global fashion brands because they have the know-how, skills, and capabilities that cannot be reproduced elsewhere. The relationship with these companies becomes fundamental for their great knowledge of the product and the manufacturing processes, and to maintain the link between craftsmanship and industry. In these times of great uncertainty, the global fashion brands are trying to maintain relationships with us [suppliers] as a source of stability and the perspective of a future restart (R8).

The difficulties related to the pandemic that global fashion brands are facing seriously affect all the actors in the supply chain.

During this crisis, global fashion brands have tried to preserve supply chain relationships by making their local suppliers work, albeit at a slow pace. However, a domino effect is generated because the collapse in sales of fashion and luxury products around the world leads to the collapse of suppliers and subcontractors. While first-tier suppliers that interact directly with global fashion brands are managing to survive through this close relationship, those most in trouble are second- and third-tier suppliers, many of whom won't survive to prolonged lockdown. In other words, the risk is that, at the end of the pandemic, the supply chain is cut down and strategic skills and knowledge are lost (R6).

If the COVID-19 pandemic will continue, the loss of orders may represent a threat for local manufacturers, due to the financial difficulties of suppliers and sub-suppliers, the progressive loss of craftsmanship skills, and human capital. We are supporting our suppliers in this scenario (R4).

Moreover, the fashion industry is characterized by the relevance of the retailing stage and its implications for BtoB markets. Retail stores have been threatened by the pandemic, due to the imposed closures and the lack of tourism in shopping cities.

Over the past few years, fashion retailing has experienced growth processes on a global scale, first with the opening of retail stores in new international markets and subsequently with the exponential growth of fashion e-commerce. An unsolved question is: will online technologies and digital tools raise their importance to solve the COVID-19 pandemic's effects and affect the interaction among players in BtoB markets?

The effects of the emergence of new online players or the investment of traditional customers in e-commerce had already been felt in the upstream supply chains before the emergence of the pandemic. The COVID-19 pandemic, by blocking the downstream retail markets with the temporary closure of many retail stores, has certainly pushed towards the online shift of sales. I believe that all companies at various stages of the supply chain should invest in the online channel, not only as a new way of selling, rather in terms of knowledge and skills to possess. It is precisely the suppliers of global fashion brands, which have invested in the digitization of processes and in the acquisition of new digital skills, that have best faced the impact of the pandemic (R2).

The hope that the pandemic will end is strong, although the second wave of coronavirus is affecting relevant markets such as Europe. As the COVID-19 virus was considered defeated in China, consumption, especially in fashion and luxury, has increased rapidly and in surprising numbers. Global fashion brands are preparing for a major recovery and the same are suggesting to their suppliers:

A post-pandemic scenario may be related to a huge bound forward. Global fashion brands will continue investing in local districts and the relationships with us [suppliers], and, as suppliers, we will strive to support global fashion brands by investing in some key aspects, such as the re-engineering and digitalization of some production processes (R6).

\section{Discussion and theoretical implications}

In this section, we aim to answer the two research questions highlighted above:

RQ1. How does the COVID-19 pandemic shape the interaction in BtoB settings?

RQ2. What types of relational dynamics stem from a pandemic crisis?

The combined analysis of theory and empirical context allows us to highlight how the COVID-19 pandemic has heavily impacted interaction in industrial markets, generating uncertainty in its founding characteristics. The fact that the COVID-19 pandemic is an unprecedented critical event at least since the postwar period, and with a global reach, allows us to propose new theoretical constructs capable of interpreting the effects on interaction. Specifically, we intend to contribute to the industrial marketing theory by showing the impact of critical events (HolmlundRytkönen and Strandvik, 2005; Edvardsson and Strandvik, 2009) on the interaction between actors and the related relational dynamics (Håkansson and Ford, 2016; Guercini and Milanesi, 2019). Our empirical research shows that there is a generalized tendency of companies to maintain existing BtoB relationships, also as a way to reduce relational uncertainty (Kreye, 2018). The effectuation logic (Sarasvathy, 2001) seems to drive BtoB companies during the crisis, as companies rely on existing relationships to face critical pandemic times and uncertainty in sales forecasting. This is particularly true especially between buyers (such as global fashion companies) and first-tier suppliers and is achieved through supporting initiatives such as placing orders aiming at maintaining an active pipeline. In this sense, our analysis shows that there is a tendency to keep existing relationships alive rather than ending them and looking for others. The uncertainty derived from the pandemic crisis is faced by anchoring to the certainty that only ongoing relationships with previously known actors can guarantee. The reason behind this behavior seems not to be related to a general problem of lack of resources, as noted in the academic debate regarding the recurs to effectuation logic (Read et al., 2009), while it relates to the conviction that to face uncertainty existing relationships should be the most valuable resources. Consequently, uncertainty from COVID-19 stresses the maintenance of relationships as the main relational dynamic in the short term. From the theoretical point of view, the concept of maintaining the relationship to which we refer here, however, is not the result of a process of confirming expectations and consequent mutual satisfaction (hence the decision to continue the relationship), typical of the development and strengthening a relationship (Holmlund-Rytkönen and Strandvik, 2005). Rather, compared to the literature, our research highlights how the COVID-19 pandemic generates the need to leverage existing relationships, given that the uncertainty in predicting future events seems to lead to the difficulty of 
establishing new interactions in conditions of social distancing and limitation of transfers of people and goods. This is also consistent with the effectuation logic (Sarasvathy, 2001) that may guide the behavior of actors in uncertain times like the one we are living in, at least to deal with the short-term effects. From the interviews, it emerges that actors in interaction start from their actual portfolio of relationships to deal with uncertainty and find responses to the pandemic, rather than setting new objectives that require the searching and activation of new relationships. Hence, what sort of dynamics may emerge in interaction? We may consider both short- and long-term effects.

Figure 1 considers the short-term effects of the pandemic according to our view. We may identify two main effects of the maintaining of existing relationships: the freezing effect in the focal dyad interaction and the ripple effect within the set of interactions and relationships surrounding the focal dyad.

The freezing effect advances the idea for the counterparties in the relationship is to maintain the existing one, given the uncertainty and the objective difficulty in establishing new relationships. The freezing effect is, therefore, the maintaining of the interaction at minimum operating levels capable of ensuring survival for both interacting actors. In this sense, no additional investments are made in the relationship, while the main aim seems to be related to maintaining "as is" the relationship. In other words, there are no intentions to develop the relationships further, while maintaining the status quo. Freezing is motivated by the conviction that previous interaction cannot be terminated due to the uncertainties, including economic-financial ones, generated by the pandemic, but must be maintained because it is essential for one's business. This is the source of supporting initiatives by leading players (such as global fashion companies in our empirical investigation).

However, the short-term effects seem to be less effective for the second- and third-tier suppliers, which seem to suffer from the fact that maintenance is seen by leading players in the supply chains as a recovery rather than a development strategy. In this sense, our analysis shows how the effects in the business network can be conceived in terms of ripple effect in interaction

Figure 1 The short-term effects of the pandemic: the freezing and the ripple effects

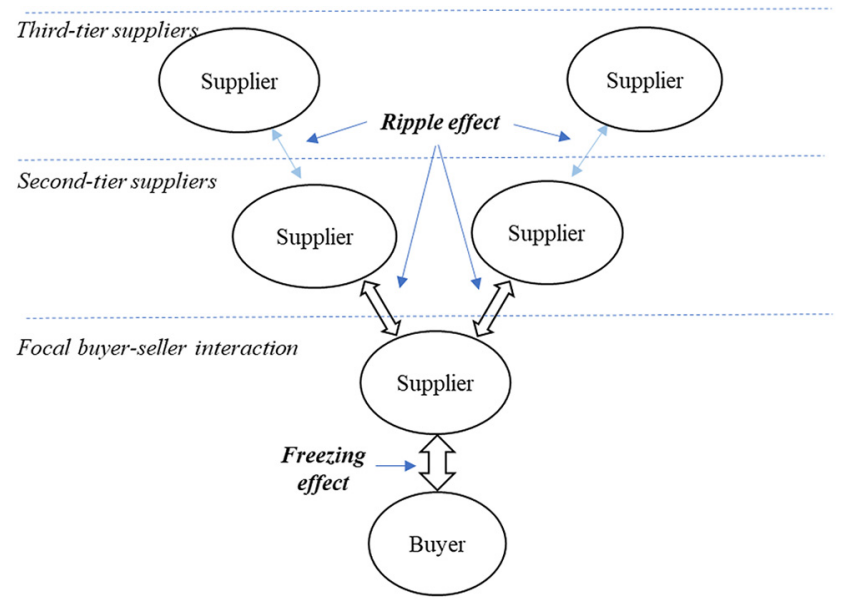

Source: Authors' elaboration based on the levels in which the supply chain is articulated. The ripple effect can be conceived as a negative effect of the pandemic related to the weakening of the freezing effects in interactions along the supply chain. In our empirical investigation, this means that the decision to maintain "as is" some focal dyads by global fashion players have weaker effects the farther are the surrounding players (as third-tier suppliers in our case) from the focal interaction (global fashion player - first-tier supplier). Compared to the literature, therefore, our analysis shows how the pandemic crisis generates in the short-term freezing of the status quo in interaction as a dynamic in response to an event that generates uncertain and unpredictable scenarios, and these effects are different depending on the actors in interaction.

Figure 2 shows the medium/long-term effects. The dynamics of the COVID-19 pandemic can be interpreted from a double perspective, pointing out a positive effect, which we label "rebound effect," and a negative effect, which we label "vicious effect." The rebound effect is generally considered in our empirical investigation as the most probable post-COVID scenario (once even the second wave hopefully will end). The rebound effect can be conceived as a sudden increase in interactive processes among existing relationships after the pandemic. Our analysis seems to highlight that the end of the pandemic may lead sales to steady and sudden growth in BtoB markets. This can be deduced from the fact that, for example, in the fashion industry the Chinese luxury market is considered as a benchmark for post-COVID consumers' decision forecasts. Moreover, China has shown economic growth even during the global pandemic. Consequently, from a theoretical point of view, the post-pandemic scenario can be interpreted as a strengthening of existing relationships and a sudden reactivation of the business network. The rebound effect connects to a greater number of interactions between the actors. Compared to the literature, however, the strengthening, in this case, is the result of a positive push in response to an unpredictable and uncertain event, not so much because of a thickening (Håkansson, 2006) generated by the normal conditions of a relationship. It is then not related to the concept

Figure 2 The long-term effect of the pandemic: the rebound effect

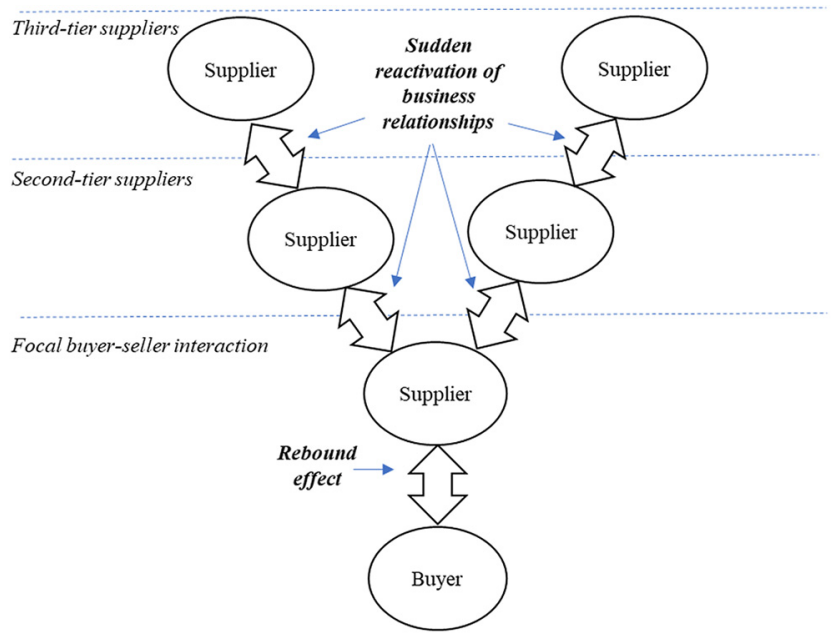

Source: Authors' elaboration 
of discontinuity in interaction, which has been studied within the business network literature (Runfola et al., 2013), as the relationships in our case were maintained and not terminated or closed. Figure 2 shows our line of reasoning.

At the same time, the long-term effects can also be interpreted in terms of relationship weakening or even ending (Havila and Medlin, 2012). Even in this case, however, the weakening, or closure of relationships is the result of the effects of the pandemic crisis and not because of unsatisfied actors or distrust. If the COVID-19 pandemic will continue, the loss of orders may represent a threat for all actors in interaction and generate a vicious effect. The vicious effect is a negative effect of the pandemic on the interaction that refers to the decay of existing interaction and their ending. This effect may imply the reconfiguration of the business network stemming from the financial difficulties of buyers, suppliers and sub-suppliers, due to the pandemic. In the case of the fashion industry, the vicious effect would be related to a progressive loss of the craftsmanship skills and "human capital" in some areas, such as the Italian one, by suppliers and sub-suppliers, with the effect of activations of new business relationships among other actors in the business network. However, the timing of the crisis (the continuation of the crisis), the business marketing strategies (intention by actors in interaction to continuously support the counterpart) and policymakers' interventions (support to industries by governments and institutions) may limit the vicious effect. Figure 3 shows a potential outcome of the pandemic with the ending of some relationships (both focal dyad and previous supply networks relationships), as well as the beginning of new relationships in the business network, because of the negative effect of the pandemic on the previous network relationships.

\section{Managerial implications and final remarks}

Whether it is a black swan or an outlier, the COVID-19 virus has made it clear how social distancing, as one of the most noticeable of the pandemic, can be a norm of behavior in the future, generating tension and changing the way people and

Figure 3 The long-term effect of the pandemic: the vicious effect

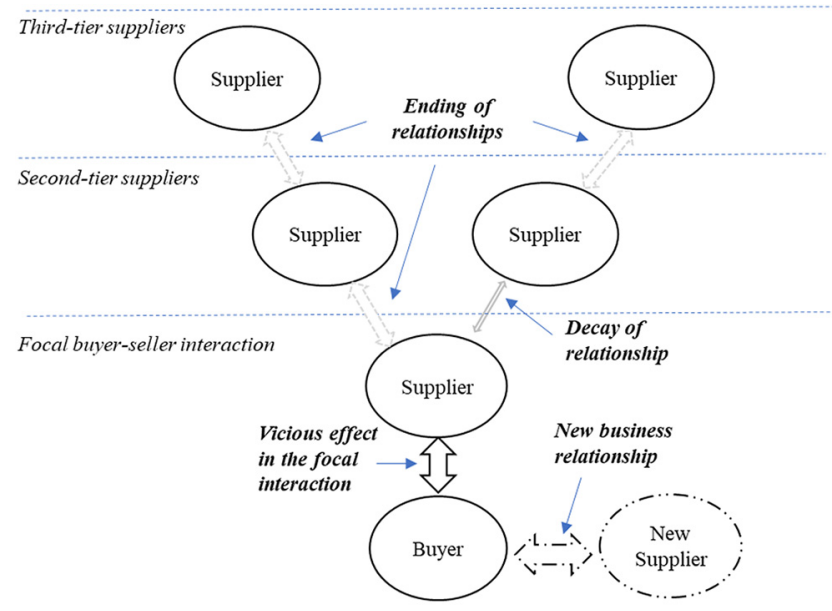

Source: Authors' elaboration companies interact. Within this ongoing scenario, the paper has adopted an explorative approach to investigate how interaction is shaped by the COVID-19 pandemic in a BtoB setting and the emerging relational dynamics. The fashion industry has been taken as an emblematic case in which interactive dynamics are a salient feature of buyer-supplier relationships. The COVID-19 pandemic might be an isolated event or not, only time will tell. At the moment of writing, the second wave of the COVID-19 pandemic is reaching and spreading across Europe and many other countries in the rest of the world. Therefore, it is not yet possible to outline a certain picture of the effects of the pandemic on some sectors and the underlying interactive dynamics in BtoB settings. However, it can be argued that the pandemic may be an opportunity, although extremely dramatic, to rethink BtoB with interaction, which is inherent in the human being and does not regard only businesses, as a key to restart. This study seeks to provide managerial implications that will allow not only responding in the short term but could be an opportunity for growth in the future. These can be summarized in the following points:

- Relying on existing business relationships to navigate over the crisis. Our research shows that managers should rely on existing relationships to face the pandemic crisis. Our findings show how companies in a network environment may take advantage of the investment made over the years in their supplier relationships. Instead of searching for new partners, we argue that, at least in the short term, one of the most valuable strategies to implement is leveraging existing relationships to stabilize the effect of the crisis. We support the idea that moving together with existing suppliers rather than moving alone in an uncertain, extraordinary and unpredictable environment. Hence, managers should exploit in the pandemic scenario the interdependencies with existing counterparts.

- The use of digital tools for interacting can be a solution for the short-term management of existing relationships and a driver of a new wave of growth in BtoB markets in the medium-long term. The pandemic had the effect of spreading the use and understanding the usefulness of new digital tools for remote interacting. This is particularly true to keep going existing supplier's relationships. The contribution of interaction for innovation, as in the case of the fashion industry, can rely on the ability to stay "close" to the customer through digital tools. This can be a new valuable area of interaction between suppliers and customers in BtoB markets raised by pandemic effects, and that can be the base for the future development of the relationship once the pandemic will end.

- Redefining times to redesign value in interactive processes. The acceleration and frenzy of the production and distribution processes, which in recent years have led many sectors to follow trends and generate continuous innovations (sometimes merely incremental and of limited innovative content), must be subject to a rethinking. The actual phase has frozen many of the relationships among actors that are waiting for a post-pandemic scenario, allowing rethinking of the value created in interaction. Fashion is an emblematic example where fast logic has been widespread within the supply chain. The trend to 
encourage the development of "fast fashion" formulas, with monthly collections and strong pressure on suppliers for quantities and delivery times, as well as for costs, could be rethought to favoring more programmed business models, with fewer collections, to make the quality and the skills in supply relationships prevail. A fundamental managerial implication is to "rewind the tape" and "reduce speed." In general, the pandemic allows managers to reflect on the importance of time spent in interaction. The product in BtoB markets comes from a complex set of interactions between actors, these interactions require time and effort. BtoB players need to emphasize the value of time spent in interaction, by coming back to more sustainable scheduling and by using new communication channels to raise awareness on these issues. This should include communication toward final consumers, the engine that activates BtoB supply chains.

- Invest in the online channel for a new logic of buyer-supplier interactions. The pandemic has made clear the importance of e-commerce platforms. The fashion system is among the most relevant in terms of online sales. The interaction between $\mathrm{BtoB}$ actors could be guided by online skills that could lead to new logic in the management of the various activities (i.e. production, transportation, delivery). Investing in digital skills to support the customer's online growth is an area that suppliers in BtoB markets will have to manage. Online channels will represent a new strategic direction to invest in. In this sense, the possibility to develop business relationships in a new normal postpandemic scenario may call for a joint growth of both suppliers and customers via online channels during the pandemic. Hence, actors, especially suppliers, should be prepared for an online channel steady growth that will change the post-pandemic BtoB relationships and be an engine for future buyer-supplier cooperation.

- Rethinking of the concept of interaction and take the most value from "physical" presence. In our findings, global players dedicated resources to those relationships with suppliers that were considered strategic and to whom they remained connected, even maintaining spatial proximity and physical interactions. Hence, it is necessary to distinguish among interactions from those that contribute to generating value if conducted face to face to those that do not. In fashion, the frenetic rhythms have multiplied the opportunities for meetings to respond to the frenzy dictated by the times. Indications also for other sectors come from the fashion industry: it is necessary to evaluate how physical presence makes an effective contribution in terms of value for customers and suppliers, identifying costs and benefits of face-to-face interactions.

The paper has also some limitations that may represent directions for future research. This study considers the fashion industry as an empirical setting, and key informants are all Italian. The reference perspective is, therefore, closely linked to the Italian context, although companies have an international or even global range of action in some cases, and to the typical relationships between buyers and suppliers that develop in the industrial districts that characterize the Italian production system. Despite the global relevance of the Italian fashion industry, this limit of perspective could be overcome by future research, directed toward a cross-national comparison with other countries in which the fashion industry is well-developed, such as France. Moreover, even if the fashion industry can be considered an emblematic case for BtoB relations, a comparison with other BtoB settings would help to make the results of this study more generalizable. Finally, the issue under study is placed in a fast-evolving context, in which the pandemic determines sudden and unpredictable changes in the business environment, increasing the level of uncertainty in which companies operate. Future research should verify the relational dynamics that emerged in the present study in the post-pandemic scenario, which could suggest new ones. The maintenance of existing relationships, which emerged as a relevant relational dynamic, could be rethought from a theoretical point of view for its role of anchor to rely on in facing uncertainty due to disruptive events like COVID-19. Moreover, it could be interesting to study how the use of digital tools, which have been implemented to support the buyer-supplier interaction during pandemic times, could be integrated into the future post-pandemic scenario both for managing existing relationships and to begin new ones. Consequently, future research could be aimed at understanding to what extent lessons learned from the COVID-19 pandemic will affect the mix of digital and physical moments in BtoB interaction.

\section{Notes}

1 www.mckinsey.com/business-functions/marketing-and-sal es/our-insights/how-b2b-decision-makers-are-respondingto-the-coronavirus-crisis.

2 www.voguebusiness.com/tag/coronavirus

3 magazine.pambianconews.com/

\section{References}

Argenti, P.A. (2020), "Communicating through the coronavirus crisis", Harvard Business Review.

Baptista, C. (2013), "Interaction processes in long-term relationships in the metal mining industry: longitudinal case studies of Capital equipment buying", Industrial Marketing Management, Vol. 42 No. 6, pp. 969-982.

Brydges, T., Retamal, M. and Hanlon, M. (2020), "Will COVID-19 support the transition to a more sustainable fashion industry?”, Sustainability: Science, Practice and Policy, Vol. 16 No. 1, pp. 298-308.

Cortez, R.M. and Johnston, W.J. (2020), “The coronavirus crisis in B2B settings: crisis uniqueness and managerial implications based on social exchange theory", Industrial Marketing Management, Vol. 88, pp. 125-135.

Crawford, G.C., Linder, C. and Lechner, C. (2017), “Outlier antecedents, processes, and consequences in the emergence of new ventures", Frontiers of Entrepreneurship Research, pp. 1-6.

Creswell, J.W. and Miller, D.L. (2000), "Determining validity in qualitative inquiry", Theory into Practice, Vol. 39 No. 3, pp. 124-130. 
Crick, J.M. and Crick, D. (2020), "Coopetition and COVID-19: collaborative business-to-business marketing strategies in a pandemic crisis", Industrial Marketing Management, Vol. 88, pp. 206-213.

Denzin, N.K. and Lincoln, Y.S. (2008), Collecting and Interpreting Qualitative Materials, Vol. 3, Sage.

Edvardsson, B. and Strandvik, T. (2009), "Critical times in business relationships", European Business Review, Vol. 21 No. 4, pp. 326-343.

Eisenhardt, K.M. and Graebner, M.E. (2007), "Theory building from cases: opportunities and challenges", Academy of Management fournal, Vol. 50 No. 1, pp. 25-32.

Ford, D., Gadde, L.E., Håkansson, H., Snehota, I. and Waluszewski, A. (2008), "Analysing business interaction", 24th IMP Conference, Uppsala.

Freytag, P.V. and Ritter, T. (2005), "Dynamics of relationships and networks - creation, maintenance and destruction as managerial challenges", Industrial Marketing Management, Vol. 34 No. 7, pp. 644-647.

Gereffi, G. (2020), "What does the COVID-19 pandemic teach us about global value chains? The case of medical supplies”, Fournal of International Business Policy, Vol. 3 No. 3, pp. 287-301.

Gronhaug, K., Hejnesand, I. and Koveland, A. (1999), "Fading relationship in business markets", Fournal of Strategic Marketing, Vol. 7 No. 3.

Guercini, S. (2004), "Developing the researcher-manager interface in the case analysis process", Management Decision, Vol. 42 Nos 3/4, pp. 464-472.

Guercini, S. (2019), "Heuristics as tales from the field: the problem of scope", Mind E Society, Vol. 18 No. 2, pp. 191-205.

Guercini, S. and Milanesi, M. (2019), "Understanding changes within business networks: evidences from the international expansion of fashion firms", fournal of Business E Industrial Marketing, Vol. 34 No. 1, pp. 192-204.

Guercini, S. and Runfola, A. (2012), "Relational paths in business network dynamics: evidence from the fashion industry", Industrial Marketing Management, Vol. 41 No. 5, pp. 807-815.

Guercini, S. and Runfola, A. (2015), “Actors' roles in interaction and innovation in local systems: a conceptual taxonomy", Fournal of Business E Industrial Marketing, Vol. 30 Nos 3/4, pp. 269-278.

Håkansson, H. (1982), International Marketing and Purchasing of Industrial Goods: An Interaction Approach, John Wiley and Sons, Chichester.

Håkansson, H. (2006), "Business relationships and networks: consequences for economic policy", The Antitrust Bulletin, Vol. 51 No. 1, pp. 143-163.

Håkansson, H. and Ford, D. (2016), "The managerial challenge of business interaction: behind the market façade", IMP fournal, Vol. 10 No. 1, pp. 154-171.

Håkansson, H. and Östberg, C. (1975), "Industrial marketing: an organizational problem?", Industrial Marketing Management, Vol. 4 Nos 2/3, pp. 113-123.

Håkansson, H. and Snehota, I. (1995), Developing Relationships in Business Networks, Routledge, London.

Håkansson, H., Ford, D., Gadde, L.E., Snehota, I. and Waluszewski, A. (2009), Business in Networks, John Wiley \& Sons.
Halinen, A. and Törnroos, J.Å. (1998), "The role of embeddedness in the evolution of business networks", Scandinavian foumal of Management, Vol. 14 No. 3, pp. 187-205.

Havila, V. and Medlin, C.J. (2012), "Ending-competence in business closure", Industrial Marketing Management, Vol. 41 No. 3, pp. 413-420.

Holmlund-Rytkönen, M. and Strandvik, T. (2005), "Stress in business relationships", fournal of Business $\mathcal{E}$ Industrial Marketing, Vol. 20 No. 1, pp. 12-22.

Ivanov, D. and Dolgui, A. (2020), "Viability of intertwined supply networks: extending the supply chain resilience angles towards survivability: a position paper motivated by COVID-19 outbreak", International fournal of Production Research, Vol. 58 No. 10, pp. 2904-2915.

Johanson, J. and Mattsson, L.G. (1987), "Interorganizational relations in industrial systems: a network approach compared with the transaction-cost approach", International Studies of Management $\mathcal{E}$ Organization, Vol. 17 No. 1, pp. 34-48.

Kang, J., Diao, Z. and Zanini, M.T. (2020), "Business-to-business marketing responses to COVID-19 crisis: a business process perspective", Marketing Intelligence E Planning, Vol. 39 No. 3.

Khusainova, R., Jong, A. D., Lee, N., Marshall, G.W. and Rudd, J. M. (2018), "(re) defining salesperson motivation: current status, main challenges, and research directions", Fournal of Personal Selling E Sales Management, Vol. 38 No. 1, pp. 2-29.

Kreye, M.E. (2018), "Interactions between perceived uncertainty types in service dyads", Industrial Marketing Management, Vol. 75, pp. 90-99.

Krings, W., Palmer, R. and Inversini, A. (2021), "Industrial marketing management digital media optimization for B2B marketing", Industrial Marketing Management, Vol. 93, pp. 174-186.

Kumar, A., Luthra, S., Mangla, S.K. and Kazançoğlu, Y. (2020), "COVID-19 impact on sustainable production and operations management", Sustainable Operations and Computers, Vol. 1, pp. 1-7.

McGowan, P. (2020a), "Sales failure: a review and future research directions", International fournal of Logistics Research and Applications, Vol. 24 No. 1, pp. 1-28.

McGowan, P. (2020b), "Use of effectuation by established micro businesses: short-term gain, long-term pain?", fournal of Business E Industrial Marketing, Vol. 36 No. 1, pp. 60-71.

Milliken, F.J. (1987), "Three types of perceived uncertainty about the environment: state, effect, and response uncertainty", Academy of Management Review, Vol. 12 No. 1, pp. 133-143.

Möller, K. K., \& Wilson, D. T. (Eds). (1995), Business Marketing: An Interaction and Network Perspective, Springer Science \& Business Media.

Olkkonen, R. and Tuominen, P. (2008), "Fading configurations in inter-organizational relationships: a case study in the context of cultural sponsorship", fournal of Business E् Industrial Marketing, Vol. 23 No. 3.

Ping, R.A. and Dwyer, F.R. (1992), "A preliminary model of relationship termination in marketing channels", Advances in Distribution Channel Research, Vol. 1, pp. 215-233.

Rapaccini, M., Saccani, N., Kowalkowski, C., Paiola, M. and Adrodegari, F. (2020), "Navigating disruptive crises through service-led growth: the impact of COVID-19 on Italian manufacturing firms", Industrial Marketing Management, Vol. 88, pp. 225-237. 
Read, S., Dew, N., Sarasvathy, S.D., Song, M. and Wiltbank, R. (2009), "Marketing under uncertainty: the logic of an effectual approach", fournal of Marketing, Vol. 73 No. 3, pp. 1-18.

Runfola, A., Guercini, S., Gregori, G.L. and Perna, A. (2013), "Discontinuity in interaction: findings from two cases in the Italian context”, Mercati e Competitivita, Vol. 1, pp. 53-72.

Sarasvathy, S. (2001), "Causation and effectuation: toward a theoretical shift from economic inevitability to entrepreneurial contingency", Academy of Management Review, Vol. 26 No. 2, pp. 243-263.

Sarasvathy, S.D. (2009), Effectuation: Elements of Entrepreneurial Expertise, Edward Elgar Publishing, Cheltenham.

Sharma, P., Leung, T.Y., Kingshott, R.P., Davcik, N.S. and Cardinali, S. (2020), "Managing uncertainty during a global pandemic: an international business perspective", fournal of Business Research, Vol. 116, pp. 188-192.

Sluss, D. and Poweley, E. (2020), "Build your team's resilience - from home", Harvard Business Review.

Tahtinen, J. and Halinen, A. (2002), "Research on ending exchange relationships: a categorization, assessment and outlook", Marketing Theory, Vol. 2 No. 2, pp. 165-188.

Taleb, N.N. (2007), The Black Swan: The Impact of the Highly Improbable, Random House.

Tunisini, A. and Bocconcelli, R. (2009), "Reconfiguring supplier relationships between local and global: history matters", Industrial Marketing Management, Vol. 38 No. 6, pp. 671-678.

UNCTAD (2020), Impact of the COVID-19 Pandemic on Trade and Development. Transitioning to a New Normal, United Nations publication, Geneva.
Walsh, M. (2020), “Develop a 'probabilistic' approach to managing uncertainty", Harvard Business Review.

Wengler, S., Hildmann, G. and Vossebein, U. (2021), "Digital transformation in sales as an evolving process", Fournal of Business $\mathcal{E}$ Industrial Marketing.

\section{Further reading}

Barnes, L., Lea-Greenwood, G., Tyler, D., Heeley, J. and Bhamra, T. (2006), "Supply chain influences on new product development in fashion clothing", Fournal of Fashion Marketing and Management: An International fournal, Vol. 10 No. 3, pp. 316-328.

Gereffi, G. (1999), "International trade and industrial upgrading in the apparel commodity chain", fournal of International Economics, Vol. 48 No. 1, pp. 37-70.

Read, S., Dew, N., Sarasvathy, S., Song, M. and Wiltbank, R. (2009), "Marketing under uncertainty: the logic of an effectual approach", Fournal of Marketing, Vol. 73 No. 3, pp. 1-18.

Törnroos, J.Å., Halinen, A. and Medlin, C.J. (2017), "Dimensions of space in business network research", Industrial Marketing Management, Vol. 61, pp. 10-19.

Turnbull, P., Ford, D. and Cunningham, M. (1996), "Interaction, relationships and networks in business markets: an evolving perspective", fournal of Business E Industrial Marketing, Vol. 11 Nos 3/4, pp. 44-62.

\section{Corresponding author}

Simone Guercini can be contacted at: simone.guercini@, unifi.it 